\title{
A Cost Effective Membrane Integrated Process for the Treatment of Vehicle Wash Wastewater
}

\author{
V. Nagamani ${ }^{1}$, Dr. R. Shyam Sunder ${ }^{2}$, Dr. V. Lakshman ${ }^{3}$ \\ ${ }^{1,2}$ University College of Technology, Osmania University, Hyderabad, India \\ ${ }^{3}$ i2P Innovations Pvt. Ltd., Director, Hyderabad, India
}

\begin{abstract}
The present investigation explores a cost effective treatment scheme for the vehicle oily wastewater generated at gas stations. The vehicle wash wastewater was subjected to combined pre-treatment consisting of 20 micron cartridge PP filter, MF Ceramic membrane (3 micron) and final stage processing involved use of Polyamide NF membrane (500 Da). The NF flux obtainedthrough CFMF as a pretreatment was close to three-fold higher than that obtained without pretreatment. The quality of the water in the form of limits of unwanted components existed in the treated water suggested that it to be fit for reuse.
\end{abstract}

Key words -Vehicle wash wastewater, nanofiltration, microfiltration, wastewater, water reuse

\section{INTRODUCTION}

In order to produce satisfactory water quality fit enough to recycle and reuse for intended purposes, options in terms of combination of techniques appears to be the way forward for certain feed types such as oily wastewater and oil-water emulsions [1]. In case of oily wastewater generated in a carwash station may contain variety of unwanted components spanning inorganic, organic and biological. The treatment options for oily wastewater may have to do with the quality of the feed and the end result envisaged [2]. In view of the environmental concerns and the need to save valuable resource, treatment of wastewater treatment for the purposes of recycling and reuse is on the rise. [3]

Many researchers reported work on various treatment options involving conventional methods such as Biological treatment (BT), Activated carbon adsorption (ACA), Electrochemical oxidation (EO), Electro-Coagulation (EC), Chemical Flocculation (CF), Chemical Coagulation (CC), Ozonation $(\mathrm{Oz})$ etc. [4-9]

In recent years, membrane processes such as Uicrofiltration (MF), ultrafiltration (UF), nanofiltration (NF), and Reverse Osmosis (RO) are increasingly being applied for treating oily wastewater.Some of the conventional techniques considered for combining with membrane techniques include, mechanical separation, dissolved air floatation, chemical de-emulsification etc. The reasons for additional membrane unit operations are being explored with a view toimprove the effluent quality as dictated by the nature of the wastewater and the effluent standard. Quite a number of works reported involving membrane based integrated techniques either as standalone or in combination with conventional techniques [10-14]
In view of the inherent advantages associated with membrane separation techniques (MST), it has attracted a great deal of interest in comparison with conventional methods with regard to treatment of wastewater in general and oily wastewater or oil-water emulsion liquid streams in particular.

Treatment of vehicle wash wastewater by MST has been reported in several studies [15-18]

Ceramic membranes have superior characteristics in the form of handling range of feed types, high temperature operability, chemical compatibility, flexibility in membrane cleaning for regeneration and extended life span etc. However, the disadvantage with ceramic membranes from conventional materials (alumina, Titania, Zirconia) is the cost of the membranes itself. With the development of the new generation of flux and fouling resistant UF /RO membranes, the performance has improved dramatically. The development of inexpensive ceramic membranes such as those made from kaolin, for example, has opened up options for considering the same for pre-treatment of a liquid wastewater and use polymeric membranes as a final stage for producing high quality water that can be reused for the intended purposes [19, 20].

In summary, MST options for treating oily wastewater are proved to be cost-effective and capable of producing high quality filtration. In order to ensure consistent performance of the membranes, it is reported that establishing an effective pre-treatment is very important [20].

In the present work, the aim of the work is to use laboratory cast kaolin membranes for pre-treatment of oily wastewater and polymeric membranes for achieving the high quality of the treated water to enable recycling and reuse. The aim of the work is to explore a simple pretreatment in the form of using a course filter, a MF ceramic membrane, and eventually a NF membrane to ensure satisfactory quality of filtrate that can be recycled and reused, thus addressing the environmental concern and saving a valuable resource like water. More specifically, the treatment scheme is applied for wastewater generated at vehicle washing gas stations. 


\section{EXPERIMENTAL}

\section{Wastewater Characteristics}

Vehicle wash wastewater was collected from a local station situated in the city of Hyderabad, India. The generation of wastewater consisted of washing activities such as wetting of the soils, cleaning agent ((a combination of SDS and EDTA) application, and final rinsing. The drain from the washings was collected in a separate tank from where 10 liter sample lots were collected for experimentation. The characteristics of the wastewater are as shown in Table 1
Table 1: Characteristics of Vehicle wash wastewater

\begin{tabular}{|c|c|}
\hline Parameter & Value \\
\hline Total solids $(\mathrm{ppm})$ & 1280 \\
\hline $\mathrm{pH}$ & 6.4 \\
\hline $\mathrm{COD}(\mathrm{ppm})$ & 460 \\
\hline Conductivity $(\mu \mathrm{S} / \mathrm{cm})$ & 680 \\
\hline
\end{tabular}

\section{Treatment processing steps}

The experimental apparatus is illustrated in Figure 1. The stirred type cell with $90 \mathrm{~mm}$ dia. was considered for the experiments. The kaolin disc MF membrane MF(KMF) was fitted with appropriate O-ring in a specially designed two chambered test cell. Commercial Polyamide NF membrane of the same diameter $(90 \mathrm{~mm}$ dia.) was fitted into a similar configured test cell. The operating conditions maintained for the experiments were stirring (rpm), feed concentration, operating pressure, and temperature.

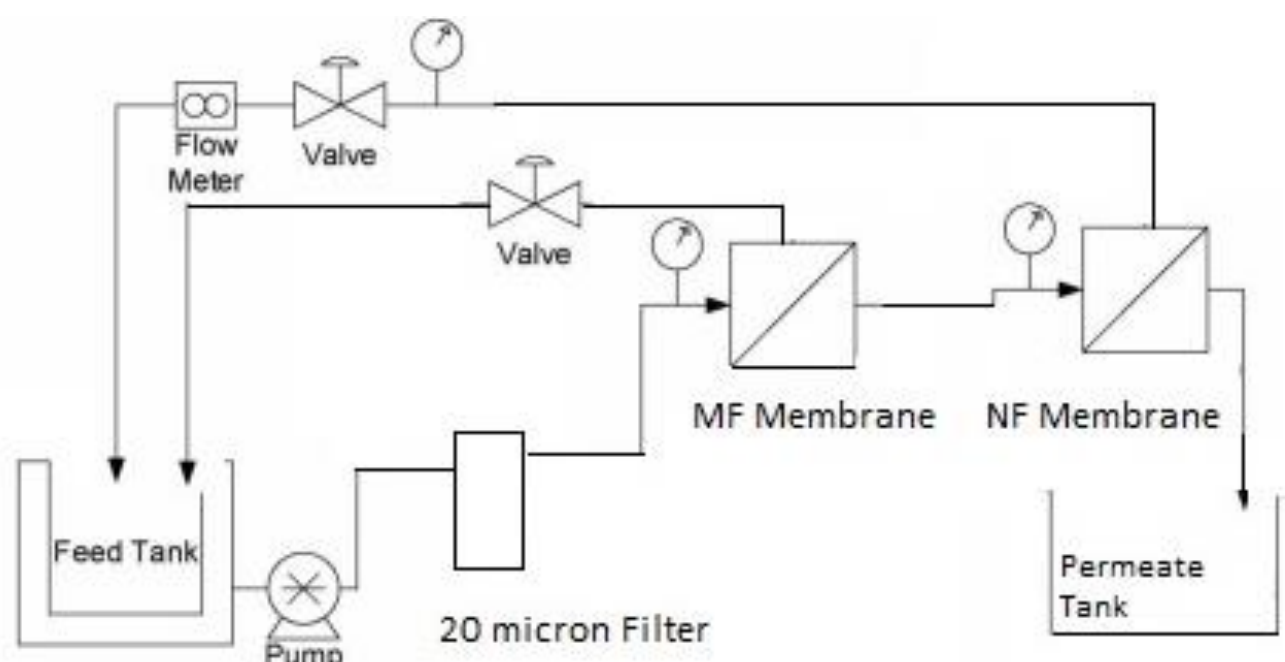

Figure 1: Integrated Membrane Experimental Set-Up

The experimental filtration systems consisted of a 20 micron pre-filter, feed pump, flow meter for monitoring flow rate and pressure gauges and thermometer for measuring the feed pressure and temperature. The permeate volumes collected with respect to time were converted into the flux values and the drop in flux by more than $40 \%$ was considered as the point for regeneration. The filtrate water quality was measured in terms of TDS, COD and color

The method for treating wastewater involved the following stages: i) Passing the wastewater through a course filter: 20 micron PP cartridge

ii) Outlet from course filtration is fed into a 3 micron kaolin based ceramic membrane

iii) The effluent from stage 2 is passed through NF membrane (500 Da Polyamide Membrane)

\section{Properties of the filters / membranes}

The properties of the filters / membranes are presented in Table 2

Table 2: Properties of filters/membranes used in the wastewater treatment

\begin{tabular}{|l|l|l|l|l|}
\hline Membrane Designation & Material & Pore size & Source & Filtration range \\
\hline PP20 & Polypropylene & 20 micron & Hitech & Course filter \\
\hline KMF $^{*}$ & Kaolin & 3 micron & Lab Cast & MF \\
\hline NF05 & Polyamide & $500 \mathrm{Da}$ & Sterlitech & NF \\
\hline
\end{tabular}

* KMF was fabricated in the laboratory with the following composition and conditions:

The ingredients in preparing the disc type kaolinite membrane included, Kaolinite (75\%), Amijel (3\%), Methocel (4\%), and Water. The steps involved in preparing the flat disc configuration of the membrane involved (i) 250 mesh screened kaolin powders, (ii) mixing the kaolin andadditives via wet milling, (iii) drying and pressing at $100 \mathrm{Mpa}$, (iv) drying (100 oC for 15 hours) and sintering (900-1250 oC for 100 min @ 4 oC per min). The resultant membrane designated as KFM had 3 micron pore size 
average, which is a subject of another paper forwarded for publication.

\section{Analytical Methods}

Samples for measurements of the feed and the permeate total solids (TS), chemical oxygen demand (COD), $\mathrm{pH}$ and total dissolved solids (TDS), Electrical conductivity (EC) were considered and analyzed by the procedure outlined in standard methods. Total solids were measured according to the evaporation methods as reported by another study [4]. COD was measured according to APHA standard methods (Model no 45600 supplied by Hach), Conductivity and pH were measured with a Hanna multimeter (Hanna's edge $(\mathrm{BEC})$. Color was measured using the Pt-Co method by a spectrophotometer (HACH, DR/5000).

\section{Membrane Experimental Procedure}

A batch type test cell with recirculation was used for the purification of oily wastewater with a combination of pretreatment filtration followed by final treatment using a nanofiltration membrane. The membrane filtration set-up involving three steps was assembled according to the flow sheet shown in Figure 1

Prior to the experiments, the initial water flux of each membrane at $25^{\circ} \mathrm{C}$ was measured with distilled water. Laboratory experiments were performed with emulsified feed obtained from vehicle wash wastewater settling tank.Oily wastewater was concentrated by ceramic membrane (3 micron) in a recirculating batch operation, whereby the clean permeate was drawn off continuously and further purified by NF in the pressure range of 75-100 psi at a temperature of $25^{\circ} \mathrm{C}$. The retentate containing the oil was recycled in an NF pilot plant with a recirculation velocity of $2 \mathrm{~m} / \mathrm{s}$, operating pressure of $25 \mathrm{psi}$, Oily wastewater was added to the process tank to maintain a certain level and at the end of the cycle, the flow to the process tank was stopped and a batch concentration was performed on the solution in the process tank.

The effectiveness of the process was determined by measurements of the volume permeate flux as well as by means of feed and permeate sample analysis of the total dissolved solids, COD, TDS, $\mathrm{pH}$ and electrical conductivity. All NF membrane measurements were performed starting after 30 minto avoid inconsistency in operating conditions.After permeate removal calculated in terms of \% volume reduction, a cleaning procedure was applied which includes rinsing with NF permeate till both the retentate and permeate streams were clear and this was followed by circulating the flow loop with of a cleaning solution. The cleaning solution was composed of $0.3 \%$
Fortlife (Dupont) dissolved in NF permeate. The cleaning was continued for $30 \mathrm{~min}$ at $35{ }^{\circ} \mathrm{C}$, with a recirculation velocity of $3 \mathrm{~m} / \mathrm{s}$ and $15 \mathrm{psi}$ of operating pressure. Finally, the system was rinsed with NF permeate and water flux was then determined.

\section{RESULTS AND DISCUSSION}

\section{Feed Conditioning}

The vehicle wash wastewater as obtained from the settling tank of the gas station was subjected to high speed stirring (7000 rpm) to convert some of the floating oil droplets into emulsions and the resultant liquid taken in a membrane feed tank to be processed in a sequential step processing. The pre-treatment step involved filtering the oily wastewater emulsion through a 20 micron PP cartridge.

\section{Membrane Performance \\ Effects of Pretreatment Process on NF Flux}

The performance of membrane in the context of treating wastewater strongly depends upon the pretreatment which contributes to reduction in membrane fouling to varying levels depending upon the type of pretreatment. Oily wastewaterin the present study was passed through 20 micron cartridge filter (CF) and then pretreatedthrough 3 micron ceramic membraneMF. NF membrane flux values obtained through course filtration integrated with MF (CFMF) as a pretreatment and which when combined with NF membrane completed the sequence.

In the membrane filtration tests, the primary cartridge filtration (20 micron) was considered mandatory knowing well that it could take care of the suspended matter. The NF05 membrane used was tested for flux variations and component rejection in the form of Total solids, TDS and COD.

After the one- hour of operation, the NF membrane flux without pretreatment, mainly microfiltration using a ceramic membrane, reduced drastically. The reasons attributed for the low flux in the NF membranes may be due to oil, grease, and other petroleum derivatives resulting from the vehicle engine washing process.

The maximum NF fluxwas obtained with CFMF as a pretreatmentduring the filtration operating time. The NF flux values were $90 \mathrm{~L} /(\mathrm{m} 2 \cdot \mathrm{h})$ with $\mathrm{CFMF}$ and $36 \mathrm{~L} /(\mathrm{m} 2 \cdot \mathrm{h})$ for NF alone. The NF flux obtainedthrough CFMF as a pretreatment was close to three-fold higher than that obtained without pretreatment. The flux variations as per the sequence of treatment are shown in Figure 2. 


\section{Flux variations with and without pretreatment}

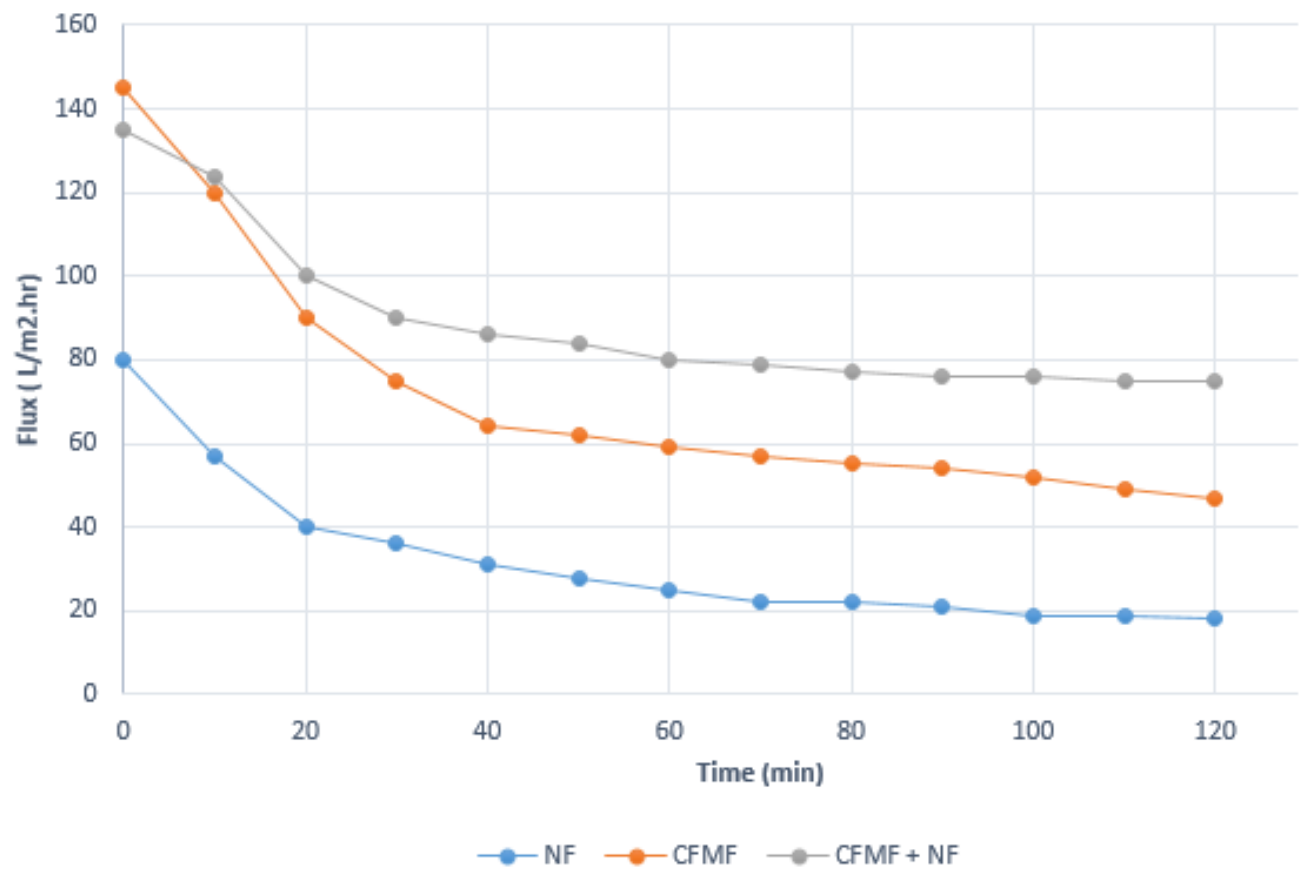

Figure 2: Flux variations with and without pretreatment of oily wastewater

\section{Stage-wise treatment effect on water characteristics}

The compositional variations as a result of stage wise treatment are measured in terms of $\mathrm{pH}$, Conductivity, COD and Color as shown in Table 3.

Table 3: Compositional variations with each stage of Treatment

\begin{tabular}{|c|c|c|c|c|}
\hline Parameter & Wastewater (Feed) & $\begin{array}{c}\text { Cartridge Filtration } \\
(\text { CF) }\end{array}$ & CFMF & CFMF + NF \\
\hline $\mathrm{pH}$ & 7.6 & 7.5 & 7.64 & 7.73 \\
\hline Conductivity $\mu \mathrm{S} / \mathrm{cm}$ & 680 & 628 & 436 & 226 \\
\hline COD $(\mathrm{ppm})$ & 460 & 430 & 68 & 4 \\
\hline Color $(\mathrm{Pt} \mathrm{Co})$ & 43 & 34 & 3 & 0.02 \\
\hline
\end{tabular}

Minimal change in the concentrations of total solids and COD of the feed post 20 micron cartridge filtration indicated that the particle sizes were less than 20 micron and the change in COD was $<2 \%$. The COD concentration can indicate pollutants attributed to detergents, oil, grease etc.

\section{CONCLUSIONS}

Bulk of course sized solid matter can be removed during the settling process. Suspended solids, colloidal matter, mostly emulsions, and dissolved matter consisting of cleaning agents or detergents are being removed significantly byMF and to a great extent by NF. Vehicle wash wastewater collected from a settling tank, if subjected to emulsification followed by low pore size membrane falling in the NF range with a pretreatment that combines a cartridge filtration in combination with a ceramic MF membrane, provides a water quality that is colorless and of quality that can be reused for the same intended purpose.

\section{REFERENCES}

[1] Li Yu,, Mei Han, Fang He, A review of treating oily wastewater, Arabian Journal of Chemistry, Volume 10, Supplement 2, May 2017, Pages S1913-S1922

[2] Rubio, J., Carissimi, E. \& Rosa, J. J. 2007 Flotation in water and wastewater treatment and reuse: recent trends in Brazil. International Journal of Environment and Pollution 30, 197-212.

[3] Zaneti, R., Etchepare, R. \& Rubio, J. Car wash wastewater reclamation. Full-scale application and upcoming features. Resources, Conservation and Recycling 55, 953-959.

[4] Rubio, J. \& Zaneti, R. N. 2009 Treatment of washrack wastewater with water recycling by advanced flocculationcolumn flotation. Desalination and Water Treatment 8, 146-153.

[5] Baddor, I. M., Farhoud, N., Mohammed, I., Abdel-Magid, D., Alshami, S., hassan Ahmad, F., Asaad, E. (2014) Study of Car Wash Wastewater Treatment by Adsorption, Proc of International Conference of Engineering, Information Technology, and Science, 2014, Infrastructure University Kuala Lumpur, Malaysia. 22ppa

[6] Aboulhassan, M. A., Souabi, S., Yaacoubi, A. \& Baudu, M. Removal of surfactant from industrial wastewaters bycoagulation flocculation process. International Journal of Environmental Science \& Technology 3, 327-332.

[7] Marco P, G Cerisola, Applicability of electrochemical methods to carwash wastewaters for reuse. Part 2: Electrocoagulation and 
anodic oxidation integrated process Article in Journal of electroanalytical chemistry 638(2):236-240

[8] Panizza, M. \& Cerisola, G. 2010b Applicability of electrochemical methods to carwash wastewaters for reuse. Part 2: Electrocoagulation and anodic oxidation integrated process. Journal of Electroanalytical Chemistry 638, 236-240.

[9] Seyyedali Mirshahghassemi1, Behnoush Aminzadeh2*, Ali Torabian3, Kamelia Afshinnia, Environmental Health Engineering and Management Journal 2017, 4(1), 37-43

[10] Pak, D. \& Chang, W. 2000 Factors affecting phosphorus removal in two biofilter system treating wastewater from car-washing facility. Water Science and Technology 41 (4-5), 487-492.

[11] Daneshyar, A. \& Ghaedi, M. Application of microfiltration membrane for treatment of car wash effluent by Taguchi method prediction. Iranian Journal of Environmental Technology 1, 1-10

[12] Boussu, K., Kindts, C., Vandecasteele, C. \& Van der Bruggen, B.Applicability of nanofiltration in the carwash industry.Separation and Purification Technology 54, 139-146.

[13] Hamada, T. \& Miyazaki, Y. 2004 Reuse of carwash water with a cellulose acetate ultrafiltration membrane aided by flocculation and activated carbon treatments. Desalination 169, 257-267.

[14] Istirokhatun, T., Destianti, P., Hargianintya, A., Oktiawan, W. \& Susanto, H.2015 Treatment of car wash wastewater by UF membranes. AIP Conference Proceedings 1699, 60025

[15] Guangyu Zhang,Longbiao Li, Yan Huang, Atsush Hozumi,Tsutomu Sonodab and Zhaohui Su, Fouling-resistant membranes for separation of oil-in-water emulsions, RSC Advances, Issue 10, 2018

[16] Jönsson, C. \& Jönsson, A.-S. 1995 The influence of degreasing agents used at car washes on the performance of ultrafiltration membranes. Desalination 100, 115-123.

[17] Lau, W. J., Ismail, F. \& Firdaus, S.2013 Car wash industry in Malaysia: treatment of car wash effluent using ultrafiltration and nanofiltration membranes. Separation and Purification Technology 104, 26-31.

[18] Ong, C. S., Lau, W. J. \& Ismail, A. F.2012 Treatment of dyeing solution by NF membrane for decolorization and salt reduction. Desalination and Water Treatment 50, 245-253.

[19] Pinto, A. C. S., de Barros Grossi, L., de Melo, R. A. C., de Assis, T. M., Ribeiro, V. M., Amaral, M. C. S. \& de Souza Figueiredo, K. C. 2017 Carwash wastewater treatment by micro and ultrafiltration membranes: effects of geometry, pore size, pressure difference and feed flow rate in transport properties. Journal of Water Process Engineering 17, 143-148.

[20] Siti Khadijah Hubadillah et al., Fabrications and applications of low cost ceramic membrane from kaolin: A comprehensive review, Ceramics International, Volume 44, Issue 5, 1 April 2018, Pages 4538-4560 